\title{
A Discriminação Indireta, Sua Natureza Jurídica e a Possibilidade de Implementação das Ações Afirmativas nas Relações de Emprego: Algumas Breves Ideias
}

\author{
HUMBERTO FERNANDES DE MOURA
}

UNICEUB - Centro Universitário de Brasília.

Submissão: 19.12 .2013

Decisão Editorial: 25.02.2014

RESUMO: 0 tema a ser desenvolvido no presente artigo diz respeito ao estudo da discriminação, especialmente da discriminação indireta nas relações de trabalho em sociedades empresárias privadas. Será exposto o conceito de discriminação indireta, sua natureza jurídica, as formas de comprovação e os possíveis remédios jurídicos punitivos e preventivos. Será exposto, mesmo que brevemente, a iniciativa do Ministério Público do Trabalho, que ajuizou algumas ações civis públicas em face dos maiores bancos privados do Distrito Federal, imputando a eles a prática de discriminação indireta, bem como foi a visão do Poder Judiciário trabalhista a respeito. Longe de buscar a resposta definitiva a questão, o presente artigo tem por objetivo apenas clarear a argumentação a respeito do tema.

PALAVRAS-CHAVE: Discriminação indireta; ações afirmativas; atuação do Poder Judiciário.

ABSTRACT: The topic to be developed in this article concerns the study of discrimination, especially indirect discrimination in labor relations in companies private entrepreneurs. It will be exposed the concept of indirect discrimination, legal status, forms of evidence and possible preventive and punitive remedies. Will be exposed, even briefly, the initiative of the Parquet, who filed some civil lawsuits in the face of the largest private banks in the Federal District, imputing to them the practice of indirect discrimination, and was the vision of the Judiciary labor respect. Far from seeking a definitive answer to the question, this article aims only lighten the arguments on the subject.

KEYWORDS: Indirect discrimination; afirmative actions; Judiciary atitude.

SUMÁRIO: 1 A Convenção n 111 da Organização Internacional do Trabalho e o conceito de discriminação; 2 Do conceito de discriminação indireta; 3 Da análise das repercussões da discriminação indireta. Exigência de regras claras de contratação, ascensão e remuneração e possibilidade, a depender de lei, de estabelecimento de cotas de contratação; 4 Discriminação indireta e a atuação do Ministério Público do Trabalho; Considerações finais; Referências.

\section{A CONVENÇÃO No 111 DA ORGANIZAÇÃO INTERNACIONAL DO TRABALHO E O CONCEITO DE DISCRIMINAÇÃO}

A Convenção no 111 da Organização Internacional do Trabalho - OIT, concernente à discriminação em matéria de emprego e profissão, ratificada pelo 
Decreto no 62.150, de 19 de janeiro de 1968, publicado no DOU de 23 de janeiro de 1968, traz definição clara a respeito do conceito de discriminação em seu art. 1으, in verbis:

Art. $1^{\circ}[\ldots]$

1. Para os fins da presente Convenção o termo discriminação compreende:

a) toda distinção, exclusão ou preferência fundada na raça, cor, sexo, religião, opinião política, ascendência nacional ou origem social que tenha por efeito destruir ou alterar a igualdade de oportunidades ou de tratamento em matéria de emprego ou profissão;

b) qualquer outra distinção, exclusão ou preferência que tenha por efeito destruir ou alterar a igualdade de oportunidades ou tratamento em matéria de emprego ou profissão, que poderá ser especificada pelo Membro interessado depois de consultas as organizações representativas de empregadores e trabalhadores, quando estas existam e outros organismos adequados.

2. As distinções, exclusões ou preferências fundadas em qualificações exigidas para um determinado emprego não são consideradas como discriminação.

3. Para os fins da presente Convenção, as palavras "emprego" e "profissão" incluem o acesso à formação profissional, ao emprego e às diferentes profissões, bem como as condições de emprego. (grifos ausentes no original)

As convenções internacionais, devidamente ratificadas pelo Brasil, segundo entendimento antes consolidado no do Supremo Tribunal Federal, teriam força de legislação ordinária ${ }^{1}$. Por outro lado, a despeito dessa visão, aquele Tribunal, a partir de voto prolatado pelo Ministro Gilmar Ferreira Mendes, e analisando a questão relativa à prisão civil viabilizada pelo Decreto-Lei no 911/1969 em face do Pacto de San Jose da Costa Rica, decidiu reconhecer aos tratados status de legislação supralegal par concluir pela impossibilidade de prisão do depositário infiel².

1 Com efeito, é pacífico, na jurisprudência desta Corte, que os tratados internacionais ingressam em nosso ordenamento jurídico tão somente com força de lei ordinária (o que ficou ainda mais evidente em face de 0 art. 105, III, da Constituição, que capitula, como caso de recurso especial a ser julgado pelo STJ, como ocorre com relação à lei infraconstitucional, a negativa de vigência de tratado ou a contrariedade a ele), não se Ihes aplicando, quando tendo eles integrado nossa ordem jurídica posteriormente à Constituição de 1988 o disposto no art. $5^{\circ}, \S 2^{\circ}$, pela singela razão de que não se admite emenda constitucional realizada por meio de ratificação de tratado." (HC 72.131, voto do Rel. p/o Ac. Min. Moreira Alves, Plenário, Julgamento em 23.11.1995, DJ de 01.08.2003)

2 Desde a adesão do Brasil, sem qualquer reserva, ao Pacto Internacional dos Direitos Civis e Políticos (art. 11) e à Convenção Americana sobre Direitos Humanos - Pacto de San José da Costa Rica (art. $7^{\circ}, 7$ ), ambos no ano de 1992, não há mais base legal para prisão civil do depositário infiel, pois o caráter especial desses diplomas internacionais sobre direitos humanos Ihes reserva lugar específico no ordenamento jurídico, estando abaixo da Constituição, porém acima da legislação interna. O status normativo supralegal dos tratados internacionais de direitos humanos subscritos pelo Brasil, dessa forma, torna inaplicável a legislação infraconstitucional com ele conflitante, seja ela anterior ou posterior ao ato de adesão. Assim ocorreu com o art. 1.287 do CC de 1916 e com o DL 911/1969, assim como em relação ao art. 652 do novo CC (Lei no 10.406/2002)" (RE 466.343, Rel. Min. Cezar Peluso, voto do Min. Gilmar Mendes, Julgamento em 03.12.2008, Plenário, 
Por outro lado, há posições no Tribunal que reconhecem aos Tratados relacionados a Direitos Humanos a natureza de normas propriamente constitucionais, por força do art. 5ำ $\S 3^{\circ}$, da Constituição ${ }^{3}$.

Essa breve exposição da jurisprudência do Supremo Tribunal Federal a respeito dos tratados internacionais humanos tem por objetivo delimitar os efeitos que a Convenção da OIT tem em relação ao ordenamento jurídico brasileiro.

Como a vedação à discriminação nas relações de emprego tem inegável interface com os direitos humanos, a convenção pode ser entendida como norma de natureza constitucional, o que confere maior importância em relação à temática que ora se apresenta.

Explicitando a Convenção no 111 , a própria Organização Internacional do Trabalho conceitua a discriminação como "o ato de tratar as pessoas de forma diferenciada e menos favorável a partir de determinadas características pessoais, tais como, entre outras, o sexo, a raça, a cor, a origem étnica, a classe social, a religião, as opiniões políticas, a ascendência nacional, que não estão relacionadas com os méritos e nem com as qualificações necessárias ao exercício do trabalho ${ }^{4 \prime \prime}$.

O conceito de discriminação na doutrina jurídica brasileira não difere significativamente. Segundo Maurício Godinho Delgado, "discriminação é a conduta pela qual se nega à pessoa, em face de critério injustamente desqualificante, tratamento compatível com o padrão jurídico assentado para a situação concreta por ela vivenciada" 5 .

E, a respeito do conceito de discriminação trazido pela Convenção, tem-se agora que expor a diferença entre a discriminação direta da discriminação indireta.

DJe de 05.06.2009, com repercussão geral). No mesmo sentido: RE 349.703, Rel. p/o Ac. Min. Gilmar Mendes, Julgamento em 03.12.2008, Plenário, DJe de 05.06.2009. Em sentido contrário: Al 403.828-

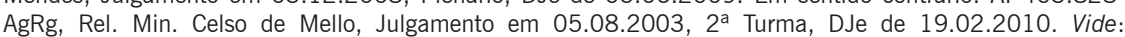
Al 601.832-AgRg, Rel. Min. Joaquim Barbosa, Julgamento em 17.03.2009, 2a Turma, DJe de 03.04.2009; HC 91.361, Rel. Min. Celso de Mello, Julgamento em 23.09.2008, $2^{\mathrm{a}}$ Turma, DJe de 06.02.2009; HC 72.131, Rel. p/o Ac. Min. Moreira Alves, Julgamento em 23.11.1995, Plenário, DJ de 01.08.2003.

3 “[...] após o advento da EC 45/2004, consoante redação dada ao $\S 3^{\circ}$ do art. $5^{\circ}$ da CF, passou-se a atribuir às convenções internacionais sobre direitos humanos hierarquia constitucional [...]. Desse modo, a Corte deve evoluir do entendimento então prevalecente [...] para reconhecer a hierarquia constitucional da Convenção. [...] Se bem é verdade que existe uma garantia ao duplo grau de jurisdição, por força do pacto de São José, também é fato que tal garantia não é absoluta e encontra exceções na própria Carta." (Al 601.832-AgRg, voto do Rel. Min. Joaquim Barbosa, Julgamento em 17.03.2009, $2^{a}$ Turma, DJE de 03.04.2009). Vide: RE 466.343, Rel. Min. Cezar Peluso, voto do Min. Gilmar Mendes, Julgamento em 03.12.2008, Plenário, DJe de 05.06.2009, com repercussão geral.

4 OIT. Manual de capacitação e informação sobre gênero, raça, pobreza, e emprego: guia para o leitor. Módulo 2 - A questão racial, pobreza, e emprego no Brasil: tendências, enfoques e políticas de promoção de igualdade. Brasília: OIT, 2005. 8 v.: il., graf., tab. p. 53.

5 DELGADO, Maurício Godinho. Curso de direito do trabalho. São Paulo: LTr. p. 773. 
Sobre a discriminação direta, o Ministro Joaquim Barbosa expõe que é

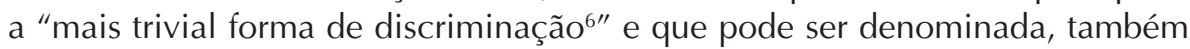
como discriminação intencional ou tratamento discriminatório. Ocorre quando "a pessoa vítima da discriminação é tratada de maneira desigual, menos favorável, seja na relação de emprego ou em qualquer outro tipo de atividade, única e exclusivamente em razão de sua raça, cor, sexo, origem ou qualquer outro fator que a diferencie da maioria dominante ${ }^{7 \prime \prime}$.

\section{DO CONCEITO DE DISCRIMINAÇÃO INDIRETA}

A discriminação denominada indireta foi conceituada pela Organização Internacional do Trabalho - OIT como "aquela que deriva de disposições e práticas aparentemente imparciais, mas que redundam em prejuízos e desvantagens de um grande número de integrantes de um determinado grupo. nem sempre está relacionada a preconceitos e estereótipos; é produzida sem que haja, necessariamente, a intenção de discriminar membros de um grupo específico" ${ }^{\prime \prime}$.

Daniel Sarmento, ao cuidar da discriminação indireta, menciona:

Também é de grande importância a discriminação indireta, correlacionada à teoria do impacto desproporcional. Essa pode ser utilizada para impugnar medidas públicas ou privadas aparentemente neutras do ponto de vista racial, mas cuja aplicação concreta resulte, de forma intencional ou não, em manifesto prejuízo para minorias estigmatizadas. A discriminação indireta difere da discriminação de fato porque na segunda a norma pode ser aplicada de forma compatível com a igualdade. Já na discriminação indireta, tem-se uma medida cuja aplicação fatalmente era desfavorecer um grupo vulnerável. ${ }^{9}$

Ou seja, enquanto a discriminação direta estaria voltada para a análise da intenção do contratante, a discriminação se preocuparia com os efeitos das práticas do contratante. Se a prática de contratação, ascensão e remuneração gerarem como impacto, como efeito, uma disparidade não baseada em critérios meritórios, poder-se-ia constatar a discriminação indireta.

Assim, a discriminação direta seria a intencional, ou seja, aquela que nega a alguém a oportunidade de emprego, ascensão profissional ou remuneração deliberadamente por critérios não meritórios, enquanto a discriminação indireta dispensaria a prova dessa intenção discriminatória, voltando os olhos para os efeitos de práticas em princípio inofensivas.

BARBOSA, Joaquim. Ação afirmativa e princípio constitucional da igualdade. São Paulo: Renovar. p. 20.

Idem, ibidem.

OIT. Op. cit., p. 54.

SARMENTO, Daniel. Direito constitucional e igualdade étnico-racial. In: PIOVESAN, Flávia; SOUZA, Douglas Martins de (coord.). Ordem jurídica e igualdade étnico-racial. Brasil: Secretaria Especial de Políticas de Promoção da Igualdade Racial da Presidência da República, 2006. 
Comprovado pelo autor o resultado díspare, a excludente de responsabilidade, como definido pela própria Convenção, seria a comprovação de que "as distinções, exclusões ou preferências fundadas em qualificações exigidas para um determinado emprego não são consideradas como discriminação".

Daí surgem alguns questionamentos: 1) Será que o conceito de discriminação indireta realmente dispensa o requisito intenção?; 2) Qual seria a natureza jurídica da responsabilidade civil admitida pela Convenção no 111 da OIT?; 3) Seria ela responsabilidade exclusivamente subjetiva?; 4) Seria ela de natureza objetiva?; 5) Ou, na verdade, a ratificação da Convenção da OIT teria incorporado ao ordenamento jurídico Brasileiro hipótese de responsabilidade por culpa presumida?; 6) Ou seja, nessa última hipótese, comprovado o resultado discriminatório, presumir-se-ia a discriminação que somente seria afastada caso o réu provasse que eventuais distinções decorreriam exclusivamente do mérito?

\section{DA ANÁLISE DAS REPERCUSSÕES DA DISCRIMINAÇÃO INDIRETA. EXIGÊNCIA DE REGRAS CLARAS DE CONTRATAÇÃO, ASCENSÃO E REMUNERAÇÃO E POSSIBILIDADE, A DEPENDER DE LEI, DE ESTABELECIMENTO DE COTAS DE CONTRATAÇÃO}

O marco legal para discussão a respeito da natureza jurídica da responsabilidade civil vem estabelecido no art. 927 do Código Civil, verbis: "Art. 927. Aquele que, por ato ilícito (arts. 186 e 187), causar dano a outrem, fica obrigado a repará-lo".

Assim, entendido que a discriminação prevista na Convenção no 111 da OIT somente gerará responsabilização caso comprovada a intenção deliberada da empregadora, a prova exigida seria dificílima. O autor teria que provar que as distinções que ocorrem na admissão, ascensão e remuneração dentro da empresa não decorrem exclusivamente de qualificações profissionais. Essa dificuldade ainda seria ampliada se os critérios de admissão, ascensão e remuneração não fossem ser claros, ou nem mesmo existirem.

Além disso, atribuir o ônus da prova exclusivamente ao autor seria praticamente tornar letra morta a Convenção $\mathrm{n}^{\circ} 111$ da OIT, bem como o conceito doutrinário de discriminação indireta.

Dessa forma, até para viabilizar a concretização do direito fundamental de não ser discriminador, ao que parece, a Convenção no 111 teria estabelecido hipótese de responsabilidade civil por culpa presumida. Como assim?

Ao autor caberia demonstrar a total disparidade entre homens e mulheres exercendo cargos de chefia ou a disparidade na admissão e remuneração entre negros, brancos e mulheres com a mesma qualificação profissional. A defesa do réu deverá se fundar na alegação de que as disparidades encontradas decorreram de critérios exclusivamente meritórios, ou seja, para evitar a responsabi- 
lização, o réu deverá indicar os critérios que adotou na admissão, ascensão e remuneração dos seus funcionários.

E se os critérios de admissão, remuneração e ascensão não existirem ou não forem claros?

Aqui surgiria uma outra interpretação a respeito da Convenção $\mathrm{n}^{\circ} 111$. Ou seja, se não admitida que ela estabelecera uma hipótese culpa presumida, pode-se ir além e entender que a Convenção estabeleceu hipótese de responsabilidade objetiva pela criação de risco juridicamente proibido.

Explica-se. Com a ausência de critérios, ou mesmo sendo esses obscuros, pode-se entender que a omissão do contratante revela a criação de um risco iminente de causar discriminação. E, se uma conduta é normalmente arriscada, pode-se aplicar a teoria do risco expressamente adotada pelo nosso Código Civil no parágrafo único do art. 927, verbis: "Parágrafo único. Haverá obrigação de reparar o dano, independentemente de culpa, nos casos especificados em lei, ou quando a atividade normalmente desenvolvida pelo autor do dano implicar, por sua natureza, risco para os direitos de outrem".

Por essa visão, além do impacto desproporcional na remuneração, ascensão e admissão, caberá ao autor comprovar que não existem na sociedade empresária regras claras de contratação, ascensão e remuneração e que a ausência de tais regras gerara o efeito discriminatório. Com isso, a responsabilidade civil da empregadora seria de rigor.

As ideias anteriormente desenvolvidas estão dentro do campo punitivo, todavia, mais do que a punição, o combate à discriminação deve ocorrer no campo preventivo ou inibitório, exigindo, por parte dos contratantes, a definição de regras claras a respeito da contratação, ascensão e remuneração.

Daí pode surgir a seguinte pergunta: Não seria exagero a exigência de uma empresa privada à definição de regras claras de contratação, remuneração e ascensão? Não deveria ser aplicada a regra de livre contratação?

Bem, como já fora indicado anteriormente, a convenção da OIT fora devidamente ratificada pelo Estado brasileiro, ou seja, evitar a discriminação na contratação, remuneração e ascensão já é obrigatório desde há muito tempo.

Além disso, cada vez mais ganha prestígio a denominada teoria da eficácia privada dos direitos fundamentais, já reconhecida no âmbito do Supremo Tribunal Federal em voto proferido pelo Ministro Gilmar Mendes no RE 201819, verbis:

As violações a direitos fundamentais não ocorrem somente no âmbito das relações entre o cidadão e o Estado, mas igualmente nas relações travadas entre pessoas físicas e jurídicas de direito privado. Assim, os direitos fundamentais assegurados pela Constituição vinculam diretamente não apenas os poderes públicos, 
estando direcionados também à proteção dos particulares em face dos poderes privados [...] A autonomia privada, que encontra claras limitações de ordem jurídica, não pode ser exercida em detrimento ou com desrespeito aos direitos e garantias de terceiros, especialmente aqueles positivados em sede constitucional, pois a autonomia da vontade não confere aos particulares, no domínio de sua incidência e atuação, o poder de transgredir ou de ignorar as restrições postas e definidas pela própria Constituição, cuja eficácia e força normativa também se impõem, aos particulares, no âmbito de suas relações privadas, em tema de liberdades fundamentais.

Diante disso, pode-se exigir em relação àquelas empresas que ocupam o denominado espaço público, ou seja, aquelas que exercem certa supremacia dentro de uma determinada área econômica, por exemplo, os bancos, a definição e publicidade de regras claras de admissão de pessoal, não a ponto de exigir-lhe o concurso público (por questão de razoabilidade), mas sim para exigir-lhe regras claras de contratação.

Todavia, mesmo que estabelecidas regras claras de contratação, ascensão e remuneração, baseadas em qualificações profissionais, exigência essa decorrente da Convenção no 111 da OIT para se evitar ou minorar a discriminação especialmente a discriminação indireta, pode ocorrer que o resultado ainda indique uma disparidade bastante desarrazoada, por exemplo, entre o número de negros e brancos.

Nesse último caso, teria cabimento, a depender de previsão legal expressa a respeito da utilização das chamadas ações afirmativas, com o estabelecimento de cotas de contratação.

Segundo Antônio Sérgio Alfredo Guimarães, as ações afirmativas são "ações que corrigem distorções nos sistemas de alocação por mérito, assentando-se nos valores individualistas e republicanos que norteiam o direito civil ocidental"10.

Toda ação considerada afirmativa enfrenta, como não poderia deixar de ser, forte argumentação contrária, entre as quais se pode indicar: as ações afirmativas significam o reconhecimento de raças e distinções de raças no Brasil e isso contraria o credo brasileiro de que somos um só povo, uma só nação; além disso, não se pode discriminar positivamente, no Brasil, porque não há limites rígidos e objetivos entre as raças e que a indefinição dos limites raciais, no Brasil, ou a ausência de tradição de identificação racial daria margem a que oportunistas se aproveitassem da situação. Por outro lado, muito mais eficaz que a implementação de ações afirmativas seria a implementação de medidas universalistas, pois não haveria na sociedade brasileira consenso sobre a de-

10 GUIMARÃES, Antônio Sérgio Alfredo. Racismo e anti-racismo no Brasil. 2. ed. rev. e atual. São Paulo: Editora 34, 2005. p. 171. 
sigualdade social provocada por diferença de cor e raça, sendo que as ações afirmativas reforçariam práticas de privilégio e de desigualdade hierárquica, ferindo os direitos constitucionais daqueles que passam a ser excluídos em consequência de sua aplicação ${ }^{11}$.

Por outro lado, arrolando os argumentos favoráveis à implementação das ações afirmativas, o mencionado autor afirma que: raça é um dos critérios reais, embora não declarados, de discriminação, utilizados em toda a sociedade brasileira, e, para combatê-lo, é essencial reconhecer sua existência, sendo que os limites rígidos e objetivos entre raças a que se reportam os opositores às ações afirmativas não existem em nenhum lugar. Afinal, o que contaria na discriminação, tanto positiva quanto negativa, é a construção social da raça (identificação racial). O risco para que oportunistas aproveitem das ações afirmativas é real, todavia ele seria mínimo, dado que exigiria o reconhecimento oficial das identidades raciais; Por outro lado, as ações afirmativas não poderiam ser substituídas por ações universalistas, vez que estas não rompem os mecanismos inerciais de exclusão e as políticas de ações afirmativas poderiam ajudar a legitimar o consenso sobre a desigualdade social provocada por diferenças de cor e raça ${ }^{12}$.

Além disso, não há que se dizer que a adoção das ações afirmativas seja considerada prática de privilégio, pois elas teriam, na verdade, efeito contrário, ou seja, inverteriam a desigualdade pondo a nu o absurdo da ordem estamental; por fim, o autor assevera que não há base legal para demonstrar a inconstitucionalidade de políticas de ação afirmativa ${ }^{13}$.

Todavia, quanto à implementação de tais ações afirmativas, nota-se grande resistência por parte do Poder Judiciário; todavia, recentemente o Supremo Tribunal Federal julgou constitucional a definição de cotas em universidades públicas ${ }^{14}$.

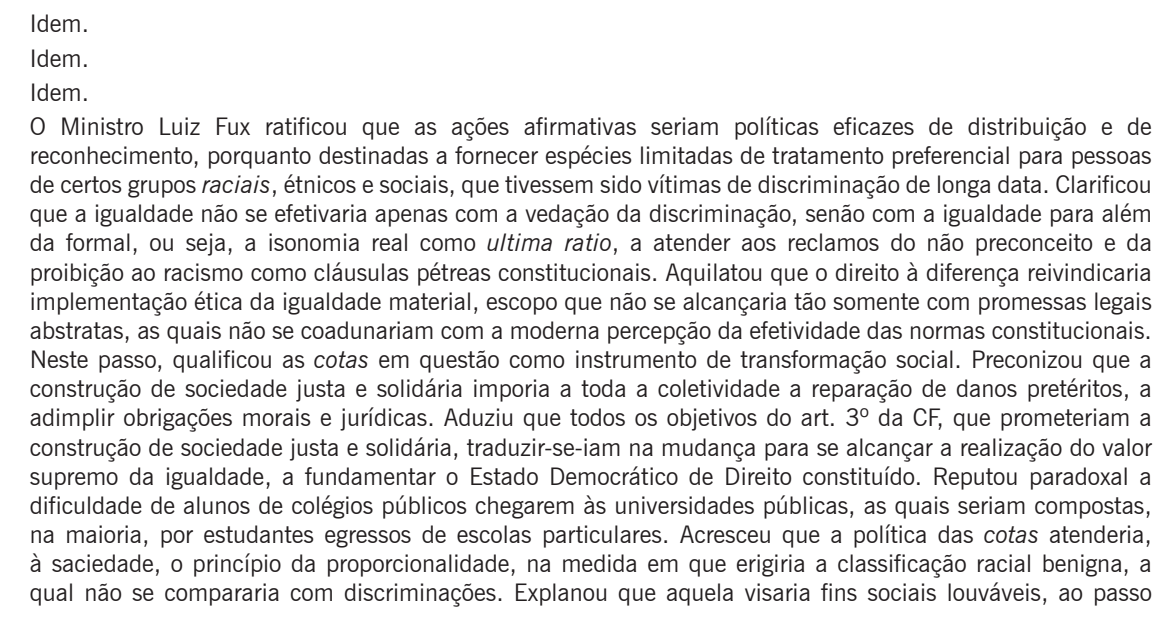

O Ministro Luiz Fux ratificou que as ações afirmativas seriam políticas eficazes de distribuição e de reconhecimento, porquanto destinadas a fornecer espécies limitadas de tratamento preferencial para pessoas de certos grupos raciais, étnicos e sociais, que tivessem sido vítimas de discriminação de longa data. Clarificou que a igualdade não se efetivaria apenas com a vedação da discriminação, senão com a igualdade para além da formal, ou seja, a isonomia real como ultima ratio, a atender aos reclamos do não preconceito e da proibição ao racismo como cláusulas pétreas constitucionais. Aquilatou que o direito à diferença reivindicaria implementação ética da igualdade material, escopo que não se alcançaria tão somente com promessas legais abstratas, as quais não se coadunariam com a moderna percepção da efetividade das normas constitucionais. Neste passo, qualificou as cotas em questão como instrumento de transformação social. Preconizou que a construção de sociedade justa e solidária imporia a toda a coletividade a reparação de danos pretéritos, a adimplir obrigações morais e jurídicas. Aduziu que todos os objetivos do art. $3^{\circ}$ da CF, que prometeriam a construção de sociedade justa e solidária, traduzir-se-iam na mudança para se alcançar a realização do valor supremo da igualdade, a fundamentar o Estado Democrático de Direito constituído. Reputou paradoxal a dificuldade de alunos de colégios públicos chegarem às universidades públicas, as quais seriam compostas, na maioria, por estudantes egressos de escolas particulares. Acresceu que a política das cotas atenderia, à saciedade, o princípio da proporcionalidade, na medida em que erigiria a classificação racial benigna, a qual não se compararia com discriminações. Explanou que aquela visaria fins sociais louváveis, ao passo 


\section{DISCRIMINAÇÃO INDIRETA E A ATUAÇÃO DO MINISTÉRIO PÚBLICO DO TRABALHO}

O Ministério Público do Trabalho, por meio de uma de suas Coordenadorias Nacionais - a Coordigualdade -, fez amplo levantamento de dados que demonstrariam práticas discriminatórias por parte de determinados bancos no Distrito Federal ${ }^{15-16}$.

Com base nos dados levantados, apontando ainda toda a experiência internacional na implementação das ações afirmativas, ajuizou algumas ações civis públicas.

As sentenças exaradas nas ações civis públicas propostas ${ }^{17}$ refutaram a existência de discriminação baseada em argumentos que podem ser assim resumidos: a discriminação não seria a causa das desigualdades observadas, uma vez que a discriminação reinante deriva, sobretudo, da qualidade social: a cor não é o tom da discriminação; na demonstração da alegada discriminação, os juízes entendem que o Ministério Público do Trabalho não se ocupou em fazer nenhum comparativo de pessoas que teriam tido tratamento desigual ou discriminatório; além disso, a discriminação não poderia ser comprovada com base em evidências estatísticas, uma vez que envolvem mera possibilidade matemática e não efetividade do fato ${ }^{18}$.

Também a posição do Tribunal Regional do Trabalho foi praticamente unânime quanto à rejeição da prática de discriminação indireta, sendo que, dos recursos julgados, apenas um dos Desembargadores julgou favoravelmente a pretensão do Ministério Público.

Alguns desses processos já foram arquivados; todavia, chama a atenção o AIRR 95241-85.2005.5.10.0013, em que o Ministério Público do Trabalho interpôs o Agravo de Instrumento em Recurso de Revista no 95241 -

que as últimas teriam cunho odioso e segregacionista. ADPF 186/DF, Rel. Min. Ricardo Lewandowski, 25 e 26.04.2012. (ADPF-186)

15 Dados colhidos pelo Ministério Público do Trabalho atestaram, por exemplo, que homens negros chegam em certo banco a receber $60 \%$ do auferido pelos homens brancos e que mulheres negara chegam a receber no mesmo banco $38 \%$ do auferido pelos homens brancos.

16 As resistências por parte do Poder Judiciário à admissão da tese da discriminação indireta foram muito bem enfrentadas em: VARELLA, Santiago Falluh. Direitos coletivos, discriminação racial e justiça. Determinantes das resistências às ações afirmativas nos discursos jurídicos. Tese de Doutorado apresentada ao Departamento de Sociologia da Universidade de Brasília (UnB) como parte dos requisitos para a obtenção do título de Doutor em 2009.

17 Colhe-se da Petição Recursal em desfavor das sentenças exaradas nas ações civis públicas ajuizadas que elas apontam a existência de discriminação indireta contra negros, mulheres e trabalhadores de mais idade no tocante à admissão, ascensão e remuneração. A prova utilizada foi primordial, mas não exclusivamente a disparidade estatística, sobejamente demonstrada e não contestada pelo banco, extraída da estatística realizada tomando por objeto a totalidade do quadro de pessoal de bancos no Distrito Federal, a partir de dados fornecidos pelo próprio banco em sede de procedimento investigatório.

18 VARELLA, Santiago Falluh. Discriminação racial e ação afirmativa no emprego sob a perspectiva dos discursos jurídicos. Trabalho apresentado no $30^{\circ}$ Encontro Anual da ANPOCS, de 24 a 28 de outubro. 
85.2005.5.10.0013 ${ }^{19}$. Nesse recurso, além dos pressupostos de admissibilidade do recurso de revista, que não fora admitido, também está sendo desenvolvida toda a argumentação que imputa ao réu a prática de discriminação indireta.

Assim, uma vez admitido o recurso de revista, o Tribunal Superior do Trabalho terá a grande possibilidade de discutir os contornos jurídicos da discriminação nas relações de trabalho, que, sem dúvida, será marcante para a história daquele Tribunal.

\section{CONSIDERACÕ̃ES FINAIS}

Assim, diante do exposto, pode-se concluir que: a Convenção $\mathrm{n}^{\circ} 111$ da OIT veda tanto a discriminação direta quanto a indireta, sendo que, para se evitar a discriminação indireta, deve-se exigir das empresas a definição de regras claras de contratação, ascensão e remuneração, sob pena de responderem pela disparidade.

A responsabilidade, como visto anteriormente, decorreria ou de culpa presumida ou da aplicação da teoria do risco. Essa conclusão independeria de intermediação legislativa, diante da eficácia horizontal dos direitos fundamentais; todavia, para fins de segurança jurídica, poderia ser editada lei estabelecendo parâmetros a serem seguidos por todas as empresas.

Além dessa exigência, também poderia ser avaliada a possibilidade de definição de cotas de contratação pelas empresas; todavia, a definição de cotas dependeria, essencialmente, de intermediação legislativa, assim como ocorre com as pessoas portadoras de necessidade especial.

Sabe-se, todavia, que há grande resistência à argumentação anteriormente desenvolvida, o que pode ser constatada pela breve análise da iniciativa do Ministério Público do Trabalho.

\section{REFERÊNCIAS}

BARBOSA, Joaquim. Ação afirmativa e princípio constitucional da igualdade. São Paulo: Renovar.

DELGADO, Maurício Godinho. Curso de direito do trabalho. São Paulo: LTr.

GUIMARÃES, Antônio Sérgio Alfredo. Racismo e anti-racismo no Brasil. 2. ed. rev. e atual. São Paulo: Editora 34, 2005.

OIT. Manual de capacitação e informação sobre gênero, raça, pobreza, e emprego: guia para o leitor. Módulo 2 - A questão racial, pobreza, e emprego no Brasil: tendências, enfoques e políticas de promoção de igualdade. Brasília: OIT, 2005.

19 Concluso desde 13.03.2012 sob a Relatoria do Ministro Walmir Oliveira da Costa. 
SARMENTO, Daniel. Direito constitucional e igualdade étnico-racial. In: PIOVESAN, Flávia; SOUZA, Douglas Martins de (coord.). Ordem jurídica e igualdade étnico-racial. Brasil: Secretaria Especial de Políticas de Promoção da Igualdade Racial da Presidência da República, 2006.

VARELLA, Santiago Falluh. Direitos coletivos, discriminação racial e justiça. Determinantes das resistências às ações afirmativas nos discursos jurídicos. Tese de Doutorado apresentada ao Departamento de Sociologia da Universidade de Brasília (UnB) como parte dos requisitos para a obtenção do título de Doutor em 2009. 